\title{
Preoperative chemotherapy prior to pulmonary metastasectomy in surgically resected primary colorectal carcinoma
}

\author{
Ishwaria M. Subbiah ${ }^{1}$, Shanda H. Blackmon ${ }^{2,4}$, Arlene M. Correa ${ }^{2}$, Bryan Kee ${ }^{3}$, Ara \\ A. Vaporciyan ${ }^{2}$, Stephen G. Swisher ${ }^{2}$ and Cathy Eng ${ }^{3}$ \\ ${ }^{1}$ Division of Cancer Medicine, The University of Texas MD Anderson Cancer Center, Houston, Texas \\ 2 Department of Thoracic and Cardiovascular Surgery, The University of Texas MD Anderson Cancer Center, Houston, Texas \\ ${ }^{3}$ Department of Gastrointestinal Medical Oncology, The University of Texas MD Anderson Cancer Center, Houston, Texas \\ ${ }^{4}$ Department of Surgery, The Methodist Hospital and Weill Cornell College of Medicine, Houston, Texas \\ Correspondence to: Cathy Eng, email: ceng@mdanderson.org \\ Keywords: colorectal, carcinoma, neoadjuvant, chemotherapy, metastasectomy \\ Received: May 10, $2014 \quad$ Accepted: July 7, $2014 \quad$ Published: July 8, 2014
}

This is an open-access article distributed under the terms of the Creative Commons Attribution License, which permits unrestricted use, distribution, and reproduction in any medium, provided the original author and source are credited.

\section{ABSTRACT}

Background: The benefit of preoperative chemotherapy prior to pulmonary metastasectomy for patients with colorectal carcinoma (CRC) is unknown. Here, we identify outcomes of preoperative chemotherapy in patients with resected primary CRC who then underwent pulmonary metastasectomy.

Methods: We queried a prospective database to identify treatment characteristics. Multivariate analyses identified predictors of overall survival (OS) and progressionfree survival (PFS).

Results: 229 patients underwent lung metastasectomy, of whom 115 proceeded to surgery without chemotherapy while 114 received preoperative regimen based on oxaliplatin $(32 \%)$, irinotecan $(46 \%)$, capecitabine $(16 \%)$, or other $(6 \%)$. Median PFS in preoperative chemotherapy vs. surgery alone arms were comparable $(p=0.004)$. Patients on oxaliplatin-based therapy had an improved OS vs. an irinotecan, capecitabine, or alternate regimen $(p=.019)$. On multivariate analysis, the irinotecan subset had a worse OS (HR 1.846; 95\% CI 1.070, 3.185) vs. surgery alone arm $(p=0.028)$. The OS of an oxaliplatin-based regimen vs. no chemotherapy was inconclusive (HR $0.57 ; 95 \%$ CI 0.237 to $1.389, \mathrm{p}=0.218$ ). Multivariate analysis demonstrated a worse PFS and OS for the male gender and an incomplete resection (R2).

Conclusion: Prospective trials on specific preoperative regimens and criteria for patient selection may identify a role for preoperative chemotherapy prior to a curative pulmonary metastasectomy.

\section{INTRODUCTION}

Pulmonary recurrence of colorectal cancer (CRC) following resection of the primary CRC lesion presents a significant clinical problem because the lung is a common site of extracolonic recurrence $[1,2]$. The optimal sequence of management of pulmonary oligometastatic disease remains unclear, although emerging data indicate a role for surgical resection in patients with metastases in the lung alone. Surgical intervention for this subset of patients has been explored with reports of $11 \%$ to $41 \%$ probability of 5-year survival in patients with resection of oligometastatic pulmonary lesions [3-5]. Indeed, the significant improvement in survival after resection of pulmonary metastases in the absence of extrapulmonary disease lesions has led to the widespread clinical practice of surgical resection in these patient populations $[1,3,5$, 6]. Furthermore, improved progression-free survival (PFS) and overall survival (OS) has been noted in patients who have undergone lung metastasectomy compared to those who deferred surgery [7]. Similarly data even suggests that lung metastases are not a poor prognostic factor for 
Table 1: Baseline patient and operative characteristics of surgery alone and the preoperative chemotherapy

\begin{tabular}{|c|c|c|c|}
\hline & Surgery Alone Arm & $\begin{array}{l}\text { Preoperative Chemotherapy } \\
\text { Arm }\end{array}$ & $p$ value \\
\hline $\mathrm{N}$ & 115 & 114 & \\
\hline \begin{tabular}{|l|l}
$\begin{array}{l}\text { Median age at time of pulmonary } \\
\text { metastasectomy, years }\end{array}$ \\
\end{tabular} & $\begin{array}{l}62 \\
(95 \% \text { CI } 50.3,73.7)\end{array}$ & $\begin{array}{l}59 \\
(95 \% \text { CI } 48.3,69.7)\end{array}$ & 0.178 \\
\hline Gender & & & 0.203 \\
\hline Male & $60(52 \%)$ & $69(61 \%)$ & \\
\hline Female & $55(48 \%)$ & $45(39 \%)$ & \\
\hline $\begin{array}{l}\begin{array}{l}\text { Stage of colorectal cancer at time of } \\
\text { diagnosis }\end{array} \\
\end{array}$ & & & 0.015 \\
\hline Early Stage (anyTanyNM0) & $85(74 \%)$ & $68(60 \%)$ & \\
\hline Stage IV (anyTanyNM1) & $24(21 \%)$ & $40(35 \%)$ & \\
\hline Unknown & $6(5 \%)$ & $6(5 \%)$ & \\
\hline \multicolumn{4}{|l|}{ Number of lung metastases } \\
\hline$\leq 2$ lesions & $102(89 \%)$ & $66(58 \%)$ & $<0.001$ \\
\hline$>2$ lesions & $13(11 \%)$ & $48(42 \%)$ & \\
\hline Size of largest lung mass $(\mathrm{cm})$, median & $\begin{array}{l}1.3 \\
(95 \% \text { CI } 0.1,2.5)\end{array}$ & $\begin{array}{l}1.8 \\
(95 \% \text { CI } 0.01,3.6)\end{array}$ & 0.009 \\
\hline
\end{tabular}

survival in patients undergoing resections for both liver and lung metastases, compared to liver metastases alone [8]. However, most analyses are retrospective single institution experiences and report a wide range of 5-year survival ranging from $21 \%$ to $61 \%$. Furthermore, OS was associated with an elevated CEA level, tumor location (unilateral vs. bilateral), and number of pulmonary metastases [9-13]. Preoperative predictors of prognosis may identify subsets of patients who may benefit from a multimodal therapeutic strategy incorporating preoperative chemotherapy prior to a potentially curative resection of oligometastatic disease. The actual benefit of preoperative chemotherapy prior to pulmonary metastasectomy, as well as the optimal regimen, are not well defined and require further analysis. Consequently, we investigate the characteristics, treatment regimens, and outcomes of patients with resected primary tumors who then underwent pulmonary metastasectomy.

\section{RESULTS}

\section{Patient characteristics}

We identified 8,712 patients with CRC who were evaluated at MD Anderson from January 1, 2000, to December 3, 2010; of these patients, 2,595 had metastases to the lung. We characterized 229 consecutive patients who underwent pulmonary metastasectomy at our institution. Patient characteristics and description of disease status are listed in Table 1. Of these 229 patients, $115(50 \%)$ underwent surgical resection alone while
$114(50 \%)$ received preoperative chemotherapy prior to resection of the pulmonary lesions. Of the 115 patients in the surgery alone arm, 85 patients had early stage disease (defined as any T, any N, M0) of colorectal cancer at the time of their initial diagnosis while 24 patients had stage IV disease (any T, any N, M1); in the preoperative chemotherapy arm, 68 patients had early stage colorectal cancer at the time of diagnosis while 40 patients had stage IV disease. The initial disease status was unknown for 6 patients in each arm. Seventeen of 38 (45\%) patients in the preoperative chemotherapy arm who underwent molecular testing demonstrated a $K R A S$ mutation in codons 12,13 , and 61 . Similarly 14 of $32(44 \%)$ tested patients in the surgery alone arm had an identified KRAS mutation. The median time to diagnosis of metastatic disease from time of resection of the primary colorectal tumor to the time of resection of the pulmonary metastases was 35.1 months (range, $1.0-143.4$ months) in the preoperative chemotherapy arm and 34.1 months (range, $2.2-149.2$ months) in the surgery alone arm. Of the 115 patients who proceed with surgery without preoperative chemotherapy, the median number of metastatic lesions within the lung was 1 (range, 1-7) and the median size of the largest lung nodule was $1.4 \mathrm{~cm}$ (range, $0.3-10 \mathrm{~cm}$ ). In the preoperative chemotherapy arm, the median number of pulmonary lesions was 2 (range, $1-16$ ) with the median size of the largest nodule being $1.8 \mathrm{~cm}$ (range, $0.2-$ $14.5 \mathrm{~cm}$ ). Baseline characteristics did vary significantly among patients receiving the four groups of preoperative regimens (Table 2). Specifically, a greater number of patients who received preoperative chemotherapy prior to pulmonary metastasectomy had stage IV disease at time of initial colorectal cancer diagnosis $(\mathrm{p}=0.015)$, more than 
Table 2: Disease characteristics across the four preoperative chemotherapy regimens among 114 patients receiving preoperative chemotherapy.

\begin{tabular}{|l|l|l|l|l|}
\hline & Oxaliplatin & Irinotecan & Capecitabine & Other \\
\hline $\mathrm{N}$ & 37 & 52 & 18 & 7 \\
\hline $\begin{array}{l}\text { Age (years) at time of resection, } \\
\text { median }\end{array}$ & 58 & 59 & 62 & 62 \\
\hline $\begin{array}{l}\text { Duration (months) of preoperative } \\
\text { chemotherapy, median }\end{array}$ & $\begin{array}{l}3.5 \\
(95 \% \text { CI } 0.5,6.5)\end{array}$ & $\begin{array}{l}4.4 \\
(95 \% \text { CI } 0.7,8.1)\end{array}$ & $\begin{array}{l}4.1 \\
(95 \% \text { CI 2.0, 6.2) }\end{array}$ & $\begin{array}{l}3.3 \\
(95 \% \text { CI 1.2, 5.4) }\end{array}$ \\
\hline Median \# of lung metastases & 2 & 3 & 2 & 3 \\
\hline $\begin{array}{l}\text { Size of largest lung metastases, } \\
\text { median (cm) }\end{array}$ & $\begin{array}{l}1.6 \\
\text { (range 0.5, 5.5) }\end{array}$ & $\begin{array}{l}1.7 \\
(\text { range } 0.2,9.3)\end{array}$ & $\begin{array}{l}1.9 \\
\text { (range 0.8, 4.5) }\end{array}$ & $\begin{array}{l}2.3 \\
\text { (range 1.3, 4.8) }\end{array}$ \\
\hline $\begin{array}{l}\text { Presence of synchronous liver } \\
\text { metastases }\end{array}$ & $15(41 \%)$ & $31(60 \%)$ & $9(50 \%)$ & $6(86 \%)$ \\
\hline $\begin{array}{l}\text { Type of resection at pulmonary } \\
\text { metastasectomy }\end{array}$ & $24(65 \%)$ & $35(67 \%)$ & $12(67 \%)$ & $3(43 \%)$ \\
\hline R0 & $8(21.6 \%)$ & $6(12 \%)$ & $4(22 \%)$ & $2(28.5 \%)$ \\
\hline R1 & $5(13.5 \%)$ & $11(21 \%)$ & $2(11 \%)$ & $2(28.5 \%)$ \\
\hline R2 & & $0(0 \%)$ & $0(0 \%)$ & $0(0 \%)$ \\
\hline Differentiation of tumor on pathology & $1(3 \%)$ & $42(81 \%)$ & $17(94 \%)$ & $6(86 \%)$ \\
\hline Well differentiated & $29(78 \%)$ & $10(19 \%)$ & $1(6 \%)$ & $1(14 \%)$ \\
\hline Moderately differentiated & $7(19 \%)$ & & \\
\hline Poorly differentiated & & & \\
\hline
\end{tabular}

Table 3: Surgical outcomes of all patients undergoing a pulmonary metastasectomy

\begin{tabular}{|l|l|l|l|}
\hline & $\begin{array}{l}\text { Surgery } \\
\text { alone arm }\end{array}$ & $\begin{array}{l}\text { Preoperative } \\
\text { chemotherapy arm }\end{array}$ & p value \\
\hline $\mathrm{N}$ & 115 & 114 & \\
\hline Initial pulmonary metastasectomy & & & 0.109 \\
\hline R0 resection (\%) & $89(77 \%)$ & $74(65 \%)$ & \\
\hline R1 resection (\%) & $14(12 \%)$ & $20(18 \%)$ & \\
\hline R2 resection (\%) & $12(11 \%)$ & $20(18 \%)$ & 0.832 \\
\hline $\begin{array}{l}\text { \# of patients with recurrence in the lung after } \\
\text { initial pulmonary metastasectomy }\end{array}$ & $37(32 \%)$ & $34(30 \%)$ & \\
\hline \# of 2nd pulmonary metastasectomy & $28(76 \%)$ & $24(71 \%)$ & \\
\hline \# of $3^{\text {rd }}$ pulmonary metastasectomy & $9(24 \%)$ & $10(29 \%)$ & \\
\hline
\end{tabular}

two pulmonary metastases $(\mathrm{p}<0.001)$, and a greater size of largest lung metastatic lesion $(\mathrm{p}=0.009)$.

\section{Preoperative chemotherapy regimen}

The median duration of preoperative therapy was 4.1 months $(95 \%$ CI $2.4,6.5)$. A total of 114 patients received preoperative chemotherapy: 41 patients $(36 \%)$ received 0 to 3 months of preoperative chemotherapy; 37 patients (32\%) received 3 to 6 months; 36 patients $(32 \%)$ received greater than 6 months. Biologic therapy was provided to a total of $67(59 \%)$ patients in combination with a cytotoxic agent; specifically, 37 (32\%) patients received an oxaliplatin-based regimen (including FOLFOX) of which 24 patients $(21 \%)$ received this regimen in combination with bevacizumab; 3 patients received FOLFOX with cetuximab and 1 patient received FOLFOX with an investigational agent. Fifty-two (46\%) patients received an irinotecan-based regimen; 23 patients $(20 \%)$ in combination with bevacizumab, 4 with cetuximab, and 3 with other biologic agents. Eighteen $(16 \%)$ patients received a capecitabine regimen, of which 6 was in combination with bevacizumab. Finally, 7 patients received other systemic regimens preoperatively including investigational targeted therapies. The surgical outcomes for all patients groups are outlined in Tables 2 and 3 


\section{Postoperative therapies after pulmonary metastasectomy}

Of the 115 patients in the surgery alone arm, 44 patients $(38 \%)$ received chemotherapy postoperative after pulmonary metastasectomy. The median time from surgery to initiation of chemotherapy postoperatively was 1.5 months $(95 \%$ CI $1.2,1.8)$. Overall, 38 (33\%) patients were treated in the absence of disease aiming to reduce the risk for disease recurrence. The remaining six patients showed evidence of active disease on their first postoperative imaging with four patients developing new pulmonary lesions, one patient with a new liver lesion, and one with new intra-abdominal adenopathy and rising CEA. Postoperatively, 19 patients received an oxaliplatin-based therapy, 13 an irinotecan containing regimen, and 11 a capecitabine-regimen. Sixteen patients received bevacizumab in conjunction with a systemic chemotherapy regimen, and two received cetuximab, one of which was as a single agent.

Of the 114 patients who received preoperative chemotherapy prior to pulmonary metastasectomy, 54 $(49 \%)$ patients received chemotherapy or radiation within 3 months postoperatively; among these 54 patients, the median time from surgery to resumption of chemotherapy postoperatively was 1.5 months $(95 \%$ CI $1.4,1.7)$. In
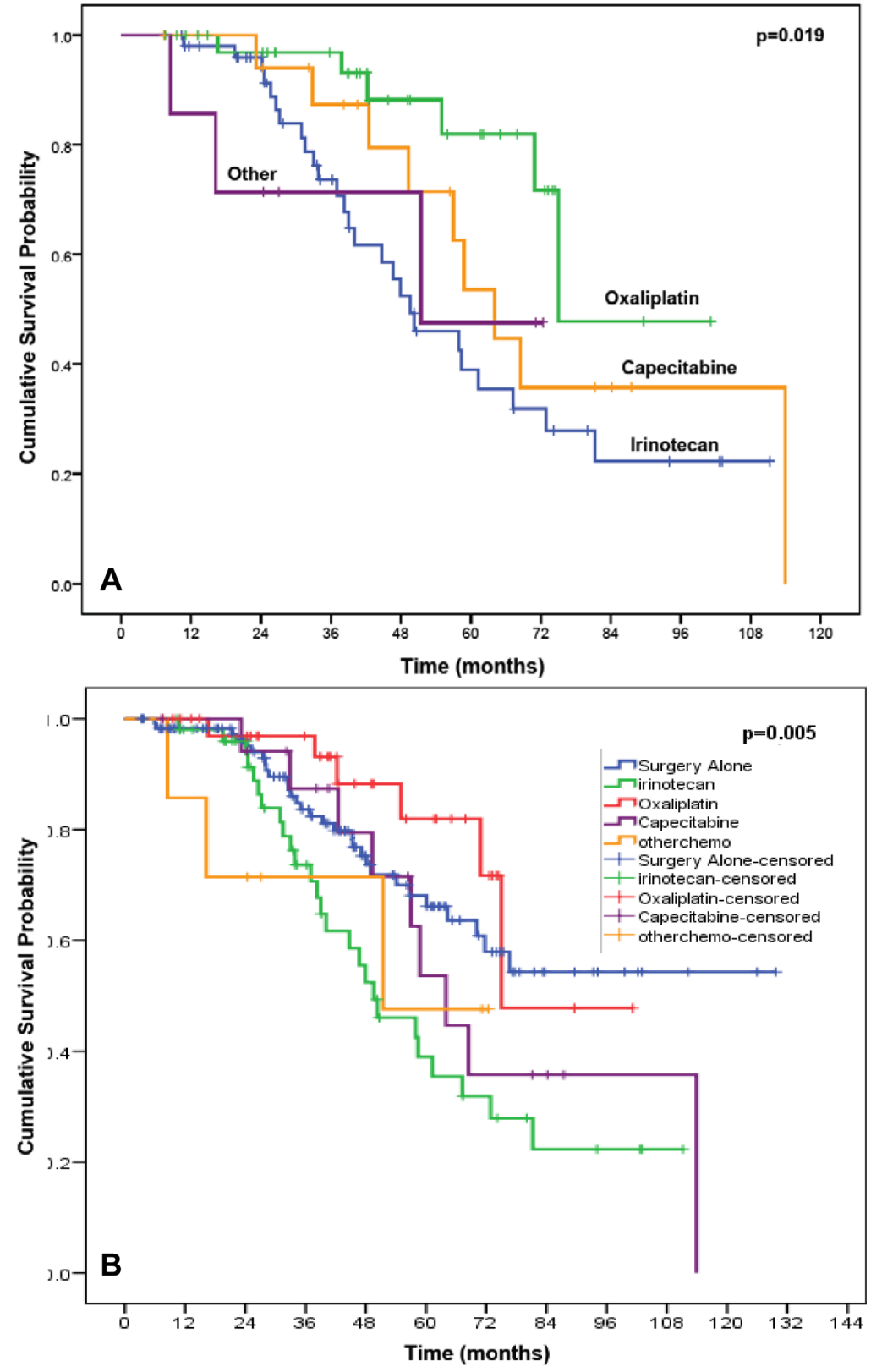

Figure 1: Kaplan-Meier curve demonstrating that the overall survival of patients in the 4 preoperative chemotherapy arms $(\mathrm{p}<.019)$, using the irinotecan-based therapy group as reference (A) and the surgery alone group as the reference (B). 
Table 4: Multivariate cox regression analysis of progression free survival across the surgery alone arm and the 4 arms of preoperative chemotherapy regimen

\begin{tabular}{|c|c|c|c|c|c|}
\hline & & & $95 \% \mathrm{Cl}$ & HR & \\
\hline & Frequency & $\begin{array}{l}\text { Hazard } \\
\text { Ratio }\end{array}$ & Lower & Upper & p-value \\
\hline Type of intervention for lung metastases & & & & & 0.264 \\
\hline Surgery Alone (Reference) & 115 & 1.000 & & & \\
\hline Irinotecan-based chemotherapy & 52 & 1.379 & 0.937 & 2.029 & 0.103 \\
\hline Oxaliplatin-based chemotherapy & 37 & 1.235 & 0.812 & 1.876 & 0.324 \\
\hline Capecitabine-based chemotherapy & 18 & 1.459 & 0.853 & 2.493 & 0.168 \\
\hline Other systemic therapy & 7 & 0.748 & 0.273 & 2.047 & 0.572 \\
\hline Gender & & & & & \\
\hline Female (Reference) & 100 & 1.000 & & & 0.036 \\
\hline Male & 129 & 1.379 & 1.021 & 1.862 & \\
\hline Type of pulmonary resection & & & & & 0.045 \\
\hline R0 (Reference) & 163 & 1.000 & & & \\
\hline R1 & 34 & 1.139 & 0.734 & 1.767 & 0.561 \\
\hline R2 & 32 & 1.780 & 1.131 & 2.803 & 0.013 \\
\hline
\end{tabular}

HR hazard ratio. Adjusted for age at time of pulmonary metastasectomy, gender, size of largest pulmonary lesion, \# of lung metastases and type of resection.

Table 5: Multivariate cox regression analysis of overall survival across the surgery alone arm and the 4 arms of preoperative chemotherapy regimen

\begin{tabular}{|c|c|c|c|c|c|}
\hline & \multirow[b]{2}{*}{ Frequency } & \multirow[b]{2}{*}{$\begin{array}{l}\text { Hazard } \\
\text { Ratio }\end{array}$} & \multicolumn{2}{|c|}{$95 \%$ C.I. for $\mathrm{HR}$} & \multirow[b]{2}{*}{ p-value } \\
\hline & & & Lower & Upper & \\
\hline Type of intervention for lung metastases & & & & & 0.054 \\
\hline Surgery Alone (Reference) & 115 & 1.000 & & & \\
\hline Irinotecan-based chemotherapy & 52 & 1.846 & 1.070 & 3.185 & 0.028 \\
\hline Oxaliplatin-based chemotherapy & 37 & 0.574 & 0.237 & 1.389 & 0.218 \\
\hline Capecitabine-based chemotherapy & 18 & 1.600 & 0.756 & 3.389 & 0.219 \\
\hline Other systemic therapy & 7 & 1.525 & 0.435 & 5.347 & 0.509 \\
\hline \multicolumn{6}{|l|}{ Gender } \\
\hline Female (Reference) & 100 & 1.000 & & & 0.016 \\
\hline Male & 129 & 1.921 & 1.130 & 3.267 & \\
\hline Type of pulmonary resection & & & & & 0.012 \\
\hline R0 (Reference) & 163 & 1.000 & & & \\
\hline $\mathrm{R} 1$ & 34 & 1.062 & 0.523 & 2.155 & 0.868 \\
\hline $\mathrm{R} 2$ & 32 & 2.802 & 1.412 & 5.561 & 0.003 \\
\hline
\end{tabular}

Adjusted for age at time of pulmonary metastasectomy, gender, size of largest pulmonary lesion, \# of lung metastases and type of resection.

$37(32 \%)$ patients, postoperative therapy was given as adjuvant therapy in the setting of no active disease with the intention of extending the recurrence-free period. The remaining 17 patients demonstrated evidence of active disease on postoperative evaluation which prompted the initiation of additional chemotherapy or radiation. Specifically, 4 patients had positive surgical margins,
5 patients had new lesions in the lungs on their first postoperative imaging. Three patients developed new hepatic lesions including one patient with concurrent new hepatic and pulmonary masses. Two patients developed enlarging lymph nodes. One patient each developed either a local recurrence at the anastomotic site of the initial colonic resection, new bone metastases, or a rising CEA. 
Of the 54 patients receiving postoperative therapy, two patients received consolidative radiation therapy: one to the positive surgical margin and a second to the regional thoracic lymph node basin where one excised node was positive for malignancy. A third patient underwent radiofrequency ablation to a solitary liver lesion. The remaining 51 patients received systemic therapy, most commonly with a regimen based on irinotecan- $(n=22)$, oxaliplatin $(n=18)$, or capecitabine $(n=9)$. Bevacizumab $(n=19)$ or an anti-epidermal growth factor receptor
(EGFR) targeting therapy (cetuximab or panitumumab, $\mathrm{n}=11$ ) was given concurrently with a cytotoxic regimen.

\section{Survival Analysis}

The median time of follow-up after the initial pulmonary metastasectomy was 33.1 months $(95 \% \mathrm{CI}$ $24.6,41.6)$ in the preoperative chemotherapy arm and 42.3 months $(95 \%$ CI 34.6, 50.0) in the surgery alone arm. The median PFS among the 115 patients in the surgery
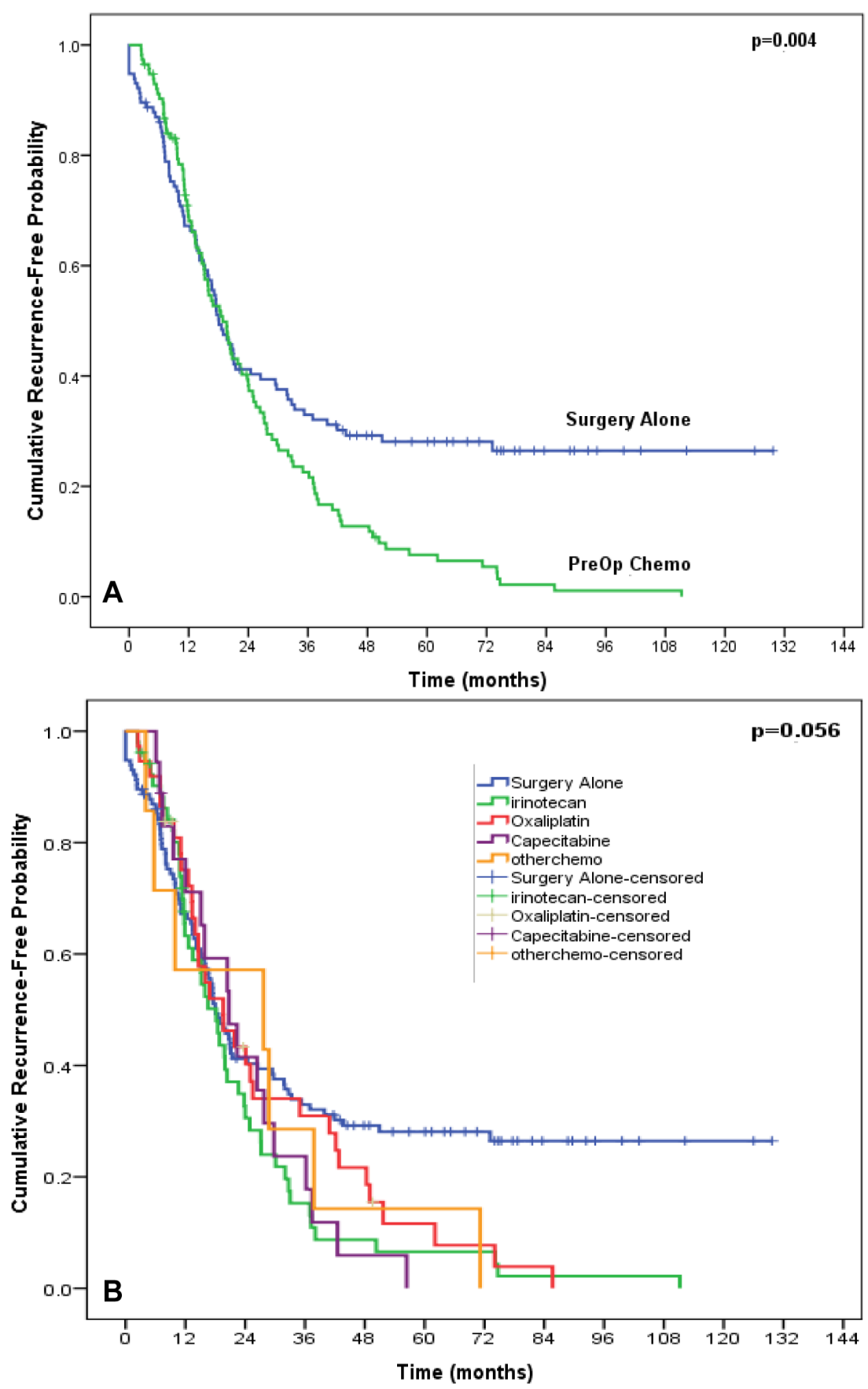

Figure 2: Kaplan-Meier curve of progression-free survival comparing the surgery alone arm versus overall preoperative chemotherapy arm (A) and each of the 4 subsets of preoperative chemotherapies (B). 
alone arm was 18.1 months (95\% CI 14.6, 21.6) while the preoperative chemotherapy arm demonstrated a median PFS of 18.8 months (95\% CI 15.1, 22.6). Of the 4 different chemotherapy arms, the median PFS was 18.2 months $(95 \%$ CI $14.2,22.2)$ in the irinotecan-based therapy arm, 19.6 months $(95 \%$ CI $11.3,27.9)$ in the oxaliplatin arm, 20.8 months $(95 \%$ CI 12.0, 29.5) in the capecitabine arm, and 27.7 months (95\% CI 1.0, 54.4) among patients receiving other systemic therapies.

For overall survival the median OS was not reached among patients in the surgery alone arm subset (mean OS 91.7 months, 95\% CI 80.9, 102.5). Among the 4 preoperative chemotherapy arms, patients receiving an irinotecan-based regimen represented the largest subset among our patients receiving preoperative chemotherapy, thereby serving as the reference group. This irinotecanreceiving subset had a worse OS (49.6 months; 95\% CI $35.3,63.9)$ in comparison to any chemotherapy regimen ( $\mathrm{p}$ 0.024). Patients receiving an oxaliplatin-based therapy demonstrated an improved OS in comparison to an irinotecan-based therapy group with a mean OS 81.0 months (95\% CI 67.7, 94.4, p = 0.019) (Figure 1); the median OS has not yet been reached in the oxaliplatingroup. Patients receiving a capecitabine-based regimen demonstrated a median OS of 64.0 months (95\% CI 52.9, 75.1) while patients on other systemic therapies did not reach median OS (mean OS 50.3 months, 95\% CI 30.7, 69.8).

The 67 patients who received a biologic drug (bevacizumab, cetuximab, or panitumumab) as part of their treatment regimen had a median PFS of 13.5 months (95\% CI 10.8, 16.2) in comparison to the 47 patients who did not receive a biologic agent (median PFS 24.9 months; 95\% CI 18.4, 31.4). However the median OS did not differ significantly between these two groups $(p=0.144)$. Receiving a bevacizumab-based regimen did not significantly impact median OS (51.5 months; 95\% CI $42.8,60.2$ ) when compared to patients receiving a preoperative regimen that did not include bevacizumab (55.1 months; 95\% CI 48.9, 61.4, $\mathrm{p}=0.435$ ).

On multivariate Cox regression analysis accounting for age at time of pulmonary metastasectomy, gender, size of largest pulmonary metastases, number of pulmonary metastases and type of resection (R0, R1, or R2), the PFS did not vary significantly among the 4 arms of preoperative chemotherapy when compared to the surgery alone arm $(p=0.264)$ (Table 4). However, on multivariate analysis of OS, the irinotecan-based chemotherapy group did demonstrate a worse OS (hazard ratio [HR] 1.846; $95 \%$ CI $1.070,3.185 ; \mathrm{p}=0.028)$ in reference to the surgery alone arm (Table 5). The oxaliplatin-based chemotherapy group trends in favor of an improved OS (HR 0.574; 95\% CI $0.237,1.389)$ when compared to the surgery alone arm (without chemotherapy) but did not reach statistical significance $(\mathrm{p}=0.218)$.

The multivariate analysis also revealed a gender predilection favoring women with men undergoing pulmonary metastasectomy demonstrating a worse PFS (HR 1.379; 95\% CI 1.021, 1.862; p=0.036) and OS (HR $1.921 ; 95 \%$ CI 1.130, 3.267; $\mathrm{p}=0.016)$. Similarly, patients who underwent an R2 resection demonstrate a poorer PFS (HR 1.780; 95\% CI 1.131, 2.803; $\mathrm{p}=0.013$ ) and OS (HR 2.802; 95\% CI 1.412, 5.561; $\mathrm{p}=0.003)$ when compared to an $\mathrm{R} 0$ resection; no difference of significance was noted in PFS (HR 1.139, $\mathrm{p}=0.561$ ) or OS (HR 1.062, $\mathrm{p}=0.863$ ) among patients who underwent an $\mathrm{R} 1$ resection when compared to an $\mathrm{R} 0$ resection.

\section{DISCUSSION}

Aggressive surgical intervention in pulmonary oligometastatic disease has shown in previous retrospective non-randomized studies to provide a 5-year survival as high as $50 \%$ with a subset of patients being cured after resection of their pulmonary metastases [2, $3,6,13-15]$. However, the exact role for preoperative chemotherapy with surgically resectable pulmonary oligometastatic disease in CRC patients has not been previously established. The characteristics of treatment failure after pulmonary metastasectomy where there is subsequent recurrence of disease may suggest that a multimodality approach may potentially improve the duration of recurrence-free survival in these patients [10, 16-18]. Our exploratory analysis suggests a potential role for an oxaliplatin-based regimen if preoperative therapy is considered prior to a potentially curative pulmonary metastasectomy thereby improving overall survival benefit in comparison to an irinotecan or capecitabine-based regimen. In the current study, the use of bevacizumab did not provide any additional benefit.

Patient selection for preoperative chemotherapy prior to resection of lung metastases remains an area of investigation. One independent analysis of our current study's patient population investigated clinical predictors of recurrence in the lung among patients after their initial CRC pulmonary metastasectomy; this work has demonstrated increasing number of lung metastases and a shorter preoperative disease free interval as predictors of increased risk for lung recurrence [12]. Furthermore, the same analysis characterized increasing age (greater than 60 years) and the male gender to independently predict shorter survival with the lowest overall survival identified among men older than 60 years of age with greater than 3 metastatic lesions in the lung (35.7 months, $\mathrm{P}<0.001)$ [12]. Indeed, the number of pulmonary metastases has predicted for shorter overall survival in several large series $[9,11$, $18,19]$. Indeed our analysis is limited by unmeasured confounding variables including performance status and comorbidities and their potential role in influencing patient selection for preoperative chemotherapy prior to a curative pulmonary metastasectomy. Additional factors limiting our analysis include the single institution, retrospective 
nature of the study in which characteristics of the disease and chemotherapy regimen was captured. However, there is homogeneity in the surgical selection for this patient population.

\section{CONCLUSION}

This exploratory analysis provides insight regarding possible therapeutic approaches to this subset of patients with oligometastatic disease in the lung with features portending for a shorter PFS and OS. Additionally, there is little literature that has clearly defined the appropriate multimodality approach to this patient population. The findings of favored overall survival after having received an oxaliplatin-based regimen when compared to no preoperative chemotherapy, remains to be investigate. Upcoming trials on specific preoperative regimens and criteria for patient selection are needed and planned. An ongoing prospective phase III trial is the first such to randomize patients with a prior resected colorectal cancer to active monitoring or active monitoring with pulmonary metastasectomy; primary endpoints include overall survival, relapse-free survival, and patient-reported quality of life [20-24]. Another planned prospective phase II study (ACCLAIM) also aims to address this very issue with concurrent molecular correlatives. Further investigation into patient characteristics may reveal patterns of recurrence that can facilitate patient selection for the most appropriate preoperative chemotherapy. Furthermore, molecular marker analysis may provide additional information regarding the primary tumor, site of metastatic disease or disease recurrence. We propose prospective pulmonary metastasectomy trials incorporating such selection may identify the subset of patients most likely to benefit from multidisciplinary approach to pulmonary oligometastatic disease.

\section{MATERIALS AND METHODS}

We queried a prospectively maintained thoracic surgery database at the University of Texas MD Anderson Cancer Center for patients with CRC who underwent their first pulmonary metastasectomy at our institution from January 1, 2000, to December 3, 2010. Eligibility criteria included the presence of unilateral or bilateral resectable lung lesions on preoperative CT scan of the chest without local colorectal recurrence or distant extrahepatic disease; the primary colorectal tumor was surgically removed with an R0 resection; treatment-naïve to systemic chemotherapy prior to lung resection. Prior resected or patients who had surgically resectable hepatic metastases were not excluded. Preoperative chemotherapy was defined as chemotherapy delivered within the 3 months before metastasectomy and not given in the adjuvant setting after resection of their primary colonic lesion.

Patients were classified as having received a preoperative regimen based on oxaliplatin, irinotecan, capecitabine, or other. Patients were allowed to receive their preoperative chemotherapy outside the institution for added convenience to the patient. All patients were required to receive clinical evaluation by the Department of Thoracic Surgery and all diagnostic imaging at MD Anderson Cancer Center. The resected pulmonary tumor size was defined as the maximal diameter on a computed tomography scan in centimeters. In the case of multiple pulmonary metastases, the diameter of the largest lesion was noted to represent the tumor size. The institutional review board granted an approval for this study with a waiver of patient consent.

\section{Survival Rate and Statistical Analysis}

We performed univariate and multivariate analyses to determine the effect of the different classes of chemotherapy regimen and various clinical variables on progression-free survival (PFS) and overall survival (OS). PFS is defined as time from date of intervention for pulmonary metastases (which will be the date of pulmonary metastasectomy surgery in the surgery alone arm, and the date of start of preoperative chemotherapy in the preoperative chemotherapy arm) to the date of first documented recurrence at any location and OS is defined as the time from the date of intervention for pulmonary metastases (as defined above) to the date of death; patients lost to follow-up or alive at the time of this analysis were censored for the date of last contact.

The multivariate analysis using the Cox proportional hazards model after backward stepwise Wald elimination was conducted using the chemotherapy regimen and clinical variables found to be significant on univariate analysis, defined as a probability value of less than 0.25 . A $p$ value of less than 0.05 on multivariate analysis was considered significant. We used Kaplan-Meier curves, Cox regression analysis and Mantel-Cox pairwise comparisons to compare the PFS and OS among the groups of patients receiving various chemotherapy regimens using the subset of patient receiving an irinotecan-based regimen or the surgery alone arm as the reference group as specified. All analyses were conducted using SPSS version 19.0 (SPSS Inc, Chicago, IL).

\section{ACKNOWLEDGEMENTS}

We thank Mr. Jonathan Phillips, Mr. Amir Mehdizadeh and Ms. Letha Gibbons for their technical assistance.

\section{Conflict of interest statement}

The authors have no conflicts of interest to disclose. 


\section{REFERENCES}

1. Galandiuk S, Wieand HS, Moertel CG, Cha SS, Fitzgibbons RJ, Jr., Pemberton JH and Wolff BG. Patterns of recurrence after curative resection of carcinoma of the colon and rectum. Surgery, gynecology \& obstetrics. 1992; 174(1):2732.

2. Inoue $\mathrm{M}$, Ohta $\mathrm{M}$, Iuchi $\mathrm{K}$, Matsumura $\mathrm{A}$, Ideguchi K, Yasumitsu T, Nakagawa K, Fukuhara K, Maeda H, Takeda S, Minami M, Ohno Y and Matsuda H. Benefits of surgery for patients with pulmonary metastases from colorectal carcinoma. The Annals of thoracic surgery. 2004; 78(1):238-244.

3. Girard P, Ducreux M, Baldeyrou P, Rougier P, Le Chevalier T, Bougaran J, Lasser P, Gayet B, Ruffie P and Grunenwald D. Surgery for lung metastases from colorectal cancer: analysis of prognostic factors. Journal of clinical oncology : official journal of the American Society of Clinical Oncology. 1996; 14(7):2047-2053.

4. Regnard JF, Grunenwald D, Spaggiari L, Girard P, Elias D, Ducreux M, Baldeyrou P and Levasseur P. Surgical treatment of hepatic and pulmonary metastases from colorectal cancers. The Annals of thoracic surgery. 1998; 66(1):214-218; discussion 218-219.

5. Iizasa T, Suzuki M, Yoshida S, Motohashi S, Yasufuku K, Iyoda A, Shibuya K, Hiroshima K, Nakatani Y and Fujisawa T. Prediction of prognosis and surgical indications for pulmonary metastasectomy from colorectal cancer. The Annals of thoracic surgery. 2006; 82(1):254-260.

6. Onaitis MW, Petersen RP, Haney JC, Saltz L, Park B, Flores R, Rizk N, Bains MS, Dycoco J, D'Amico TA, Harpole DH, Kemeny N, Rusch VW and Downey R. Prognostic factors for recurrence after pulmonary resection of colorectal cancer metastases. The Annals of thoracic surgery. 2009; 87(6):1684-1688.

7. Tampellini M, Ottone A, Bellini E, Alabiso I, Baratelli C, Bitossi R, Brizzi MP, Ferrero A, Sperti E, Leone F, Miraglia S, Forti L, Bertona E, Ardissone F, Berruti A, Alabiso O, et al. The role of lung metastasis resection in improving outcome of colorectal cancer patients: results from a large retrospective study. The oncologist. 2012; 17(11):14301438.

8. Brouquet A, Vauthey JN, Contreras CM, Walsh GL, Vaporciyan AA, Swisher SG, Curley SA, Mehran RJ and Abdalla EK. Improved survival after resection of liver and lung colorectal metastases compared with liveronly metastases: a study of 112 patients with limited lung metastatic disease. Journal of the American College of Surgeons. 2011; 213(1):62-69; discussion 69-71.

9. McAfee MK, Allen MS, Trastek VF, Ilstrup DM, Deschamps $\mathrm{C}$ and Pairolero PC. Colorectal lung metastases: results of surgical excision. The Annals of thoracic surgery. 1992; 53(5):780-785; discussion 785-786.

10. Rama N, Monteiro A, Bernardo JE, Eugenio L and Antunes MJ. Lung metastases from colorectal cancer: surgical resection and prognostic factors. European journal of cardio-thoracic surgery : official journal of the European Association for Cardio-thoracic Surgery. 2009; 35(3):444449.

11. Zink S, Kayser G, Gabius HJ and Kayser K. Survival, disease-free interval, and associated tumor features in patients with colon/rectal carcinomas and their resected intra-pulmonary metastases. European journal of cardiothoracic surgery : official journal of the European Association for Cardio-thoracic Surgery. 2001; 19(6):908913.

12. Blackmon SH, Stephens EH, Correa AM, Hofstetter W, Kim MP, Mehran RJ, Rice DC, Roth JA, Swisher SG, Walsh GL and Vaporciyan AA. Predictors of recurrent pulmonary metastases and survival after pulmonary metastasectomy for colorectal cancer. The Annals of thoracic surgery. 2012; 94(6):1802-1809.

13. Yedibela S, Klein P, Feuchter K, Hoffmann M, Meyer T, Papadopoulos T, Gohl J and Hohenberger W. Surgical management of pulmonary metastases from colorectal cancer in 153 patients. Annals of surgical oncology. 2006; 13(11):1538-1544.

14. Mitry E, Guiu B, Cosconea S, Jooste V, Faivre J and Bouvier AM. Epidemiology, management and prognosis of colorectal cancer with lung metastases: a 30-year population-based study. Gut. 2010; 59(10):1383-1388.

15. Vogelsang H, Haas S, Hierholzer C, Berger U, Siewert JR and Prauer H. Factors influencing survival after resection of pulmonary metastases from colorectal cancer. The British journal of surgery. 2004; 91(8):1066-1071.

16. Rena O, Casadio C, Viano F, Cristofori R, Ruffini E, Filosso $\mathrm{PL}$ and Maggi G. Pulmonary resection for metastases from colorectal cancer: factors influencing prognosis. Twentyyear experience. European journal of cardio-thoracic surgery : official journal of the European Association for Cardio-thoracic Surgery. 2002; 21(5):906-912.

17. McCormack PM, Burt ME, Bains MS, Martini N, Rusch VW and Ginsberg RJ. Lung resection for colorectal metastases. 10-year results. Arch Surg. 1992; 127(12):14031406.

18. Pfannschmidt J, Bade S, Hoheisel J, Muley T, Dienemann $\mathrm{H}$ and Herpel E. Identification of immunohistochemical prognostic markers for survival after resection of pulmonary metastases from colorectal carcinoma. The Thoracic and cardiovascular surgeon. 2009; 57(7):403-408.

19. Okumura S, Kondo H, Tsuboi M, Nakayama H, Asamura $\mathrm{H}$, Tsuchiya R and Naruke T. Pulmonary resection for metastatic colorectal cancer: experiences with 159 patients. The Journal of thoracic and cardiovascular surgery. 1996; 112(4):867-874.

20. Fiorentino F, Vasilakis $\mathrm{C}$ and Treasure T. Clinical reports of pulmonary metastasectomy for colorectal cancer: a citation network analysis. British journal of cancer. 2011; 104(7):1085-1097. 
21. Hornbech K, Ravn J and Steinbruchel DA. Outcome after pulmonary metastasectomy: analysis of 5 years consecutive surgical resections 2002-2006. Journal of thoracic oncology : official publication of the International Association for the Study of Lung Cancer. 2011; 6(10):1733-1740.

22. Borasio P, Gisabella M, Bille A, Righi L, Longo M, Tampellini $\mathrm{M}$ and Ardissone F. Role of surgical resection in colorectal lung metastases: analysis of 137 patients. International journal of colorectal disease. $2011 ; 26(2)$ :183190.

23. Treasure T, Fallowfield L, Lees B and Farewell V. Pulmonary metastasectomy in colorectal cancer: the PulMiCC trial. Thorax. 2012; 67(2):185-187.

24. Fiorentino F, Hunt I, Teoh K, Treasure $\mathrm{T}$ and Utley M. Pulmonary metastasectomy in colorectal cancer: a systematic review and quantitative synthesis. Journal of the Royal Society of Medicine. 2010; 103(2):60-66. 